\title{
Design, Analysis and Dynamic Performance of Radial Magnetic Coupling
}

\author{
Yusuf Akcay ${ }^{1}$, Paolo Giangrande ${ }^{1}$, Michael Galea ${ }^{1,2}$ \\ ${ }^{1}$ PEMC Research Group, University of Nottingham, Nottingham, United Kingdom \\ ${ }^{2}$ Key Laboratory of More Electric Aircraft Technology of Zhejiang Province, University of Nottingham \\ Ningbo China \\ Email: yusuf.akcay1@nottingham.ac.uk
}

\begin{abstract}
Contactless torque/speed transmission is gaining an ever-increasing interest in industry and mobile applications, since the mechanical wear-out is avoided resulting in lower maintenance costs. The radial topology is one possible configuration for magnetic couplings (MCs) and its main components are two concentric rings equipped with permanent magnets (PMs). The transmitted torque value depends on an angular shift between the inner and outer rings and greater shift angles lead to higher transfer torque. Hence, the shift angle is a crucial design parameter and defines the dynamic performance of the MC. In this paper, a radial MC is designed based on 2D analytical subdomain approach and validated against 3D finite element simulations. The 3D model is then employed to evaluate the torque transmission capability of the designed radial MC. Finally, the dynamic performance is investigated in terms of disturbance rejection under several load torque values including the mechanical features of the considered test bench.
\end{abstract}

\section{INTRODUCTION}

Relying on the interaction between the magnetic fields produced by two sets of permanent magnets (PMs) mounted on as many free-rotating bodies, MCs enable the torque transfer from a prime mover to a load. The transmission occurs in absence of mechanical contact and keeping unchanged the transmission rate [1]. In the 1970s and 1980s, the investigation and development of rare-earth magnets, i.e. neodymium and samarium-cobalt magnets, enabled very strong magnetic fields by comparison with ferrite or ceramic magnets [2], [3]. As a result of that, the magnetic couplings/gearboxes gain a significant interest and become a valid alternative to their mechanical counterparts [4]-[9]. The benefit rising from the adoption of MCs ranges from high efficiency to maintenance-free operations enabling and promoting their employment in modern applications [10][13]. In addition, inherently overload-protection, reduced noise and vibration are some of the main remarkable attributes of the MCs [14], [15].

However, having a contactless torque/speed transmission unveils some issues such as highly-compliance characteristics which may cause pole-slipping depending on the dynamic behavior of the systems. Thus, the design process must be carefully organized in order to avoid detrimental failures on the systems [16], [17]. Previously, in literature, a dynamic characteristic of a $\mathrm{MC}$ is represented by using a well-known two-inertia system coupled with a linear torsion spring. Hence, MCs can be seen as magnetic gearbox with 1:1 transmission ratio [18]. A standard PI control algorithm is developed for the pole-slipping detection and prevention [19]-[22]. In [23], a more advanced control strategy is developed for a recovery after the coupling goes to pole-slipping region.

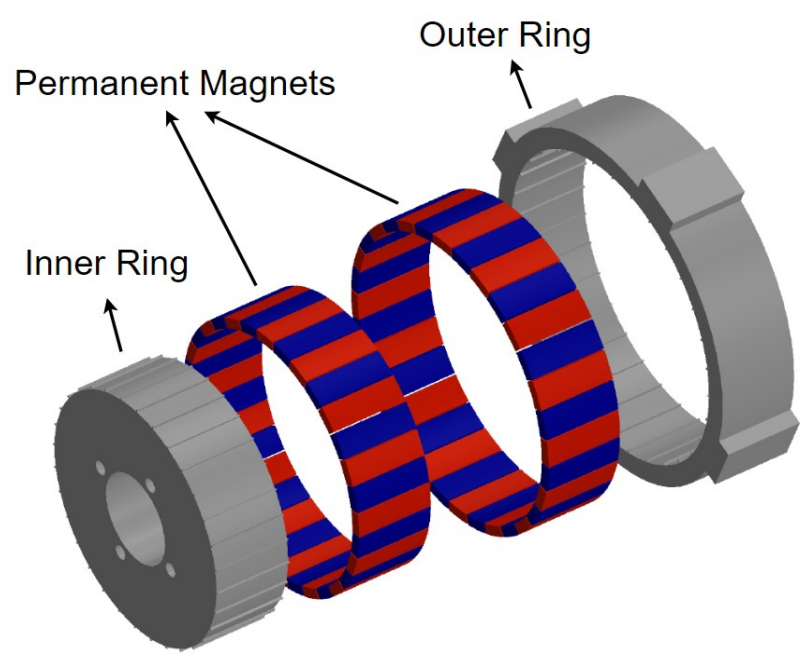

Fig. 1. Exploded view of the CMC.

A typical architecture for $\mathrm{MC}$ is represented by the radial structure, which generally features a superior torque density compared to the axial counterpart [24].

In this work, a 2D analytical tool is initially built to quickly size a radial MC for the purpose of enhancing the transmitted torque. In Fig. 1, an exploded view of the radial MC is reported, where its constituting parts are highlighted. Thus, the influence that parameters, such as pole-pair number and PM span, play on the shift angle is evaluated. The radial MC design is then refined and validated through a 3D finite element (FE) model, which is also used to assess the dynamic behavior of the MC for several load conditions.

\section{DESIGN OF RADIAL MC}

In this section, a MC with specified target values is designed by using the 2D analytical tool developed according to the subdomain approach, which is briefly introduced, and the results of the sensitivity analysis are discussed. The proposed MC aims to develop a peak static torque of $100 \mathrm{Nm}$ at $1500 \mathrm{rpm}$.

First, the MC design parameters are identified and represented in a $2 \mathrm{D}$ polar coordinate for the analytical evaluation. The size parameters are given in Table I, while the geometric view of the radial MC with associated subdomains of each region is detailed in Fig. 2. The 2D analytical method is implemented in order to investigate effects of the essential design parameters such as the airgap thickness, pole-pairs number and PM thicknesses. As it is mentioned in [24], the peak static torque is highly influenced by pole-pair numbers. 
The paper shows that the peak static torque is proportional to both the PM thickness and active length. Thus, it is known that an increase in the aforementioned parameters linearly enhances the peak static torque. However, on the other hand, there is a nonproportional relation between the pole-pair numbers and the peak static torque. A radial MC with the same size parameters has different peak static torque values versus the pole-pair numbers.

The initial values listed in Table 1 are for a preliminary assessment. The values imply the correctness and accuracy of the analytical method compared with the 3D FEM simulation results. As it can be seen in Fig. 2, the coupling simply consists of three subdomains: i.e. the inner and outer PM, and the airgap. Each region has its vector potential derived by the resolution of Laplace's and Poisson's equation for the airgap and PM subdomains, respectively. The potential functions are solved by using their associated boundary conditions which are detailed in [24].

TABLE I

THE RADIAL MC PARAMETERS FOR THE 2D ANALYTICAL EXERCISE

\begin{tabular}{|c|c|c|}
\hline Symbol & Parameters & Values \\
\hline$R_{1}$ & Back Iron Inner Radius & $50 \mathrm{~mm}$ \\
\hline$R_{2}$ & Inner PM Inner Radius & $65 \mathrm{~mm}$ \\
\hline$R_{3}$ & Inner PM Outer Radius & $70 \mathrm{~mm}$ \\
\hline$R_{4}$ & Outer PM Inner Radius & $72 \mathrm{~mm}$ \\
\hline$R_{5}$ & Outer PM Outer Radius & $77 \mathrm{~mm}$ \\
\hline$R_{6}$ & Outer Back Iron Outer Radius & $92 \mathrm{~mm}$ \\
\hline$l_{a}$ & Airgap Thickness & $2 \mathrm{~mm}$ \\
\hline$p$ & Number of Pole-Pair & 12 \\
\hline$l_{m}$ & PM Thickness & $5 \mathrm{~mm}$ \\
\hline$l_{b}$ & Back Iron Length & $15 \mathrm{~mm}$ \\
\hline$B_{m}$ & PM Openings & $95 \%$ \\
\hline$l_{s}$ & Active Part Length & $15 \mathrm{~mm}$ \\
\hline$B_{r}$ & Remanence of PMs & $1.29 \mathrm{~T}$ \\
\hline
\end{tabular}

The first comparison is given for the radial and tangential components of the flux density distribution in the airgap between the 2D analytical method and 3D FEM, and the corresponding results are shown in Fig. 3. The results are revealed under the peak static torque equilibrium, where the shift angle is equal to $7.5^{\circ}$ when 12 pole-pairs are considered (see Table I).

The static torque comparison is provided in Fig. 4 between the $2 \mathrm{D}$ analytical method and 3D FEM. The static torque takes $30^{\circ}$ shift to get one cycle. The torque is null at the zero-equilibrium point as indicated in Fig. 4. In any load conditions, the motor and load side of the coupling creates a shift to produce required torque values. Nevertheless, the synchronous rotation is kept unless an excessive load, which can be seen as a disturbance, is applied. In case of an overload condition, the coupling goes to unstable region which cause pole-slipping phenomena.

The results revealed in Fig. 3 and 4 establish a good matching. Indeed, the components of the flux density distribution exhibit 1.5 and 0.5 percent maximum relative error in the radial and tangential components, respectively whilst it is 3 percent in the static torque. Thus, the trade-off analysis of the radial $\mathrm{MC}$ is completed under the 2D analytical method since it allows a quick identification of the optimum design parameters for the MC. In fact, the 3D FEM is significantly time consuming to solve [25].

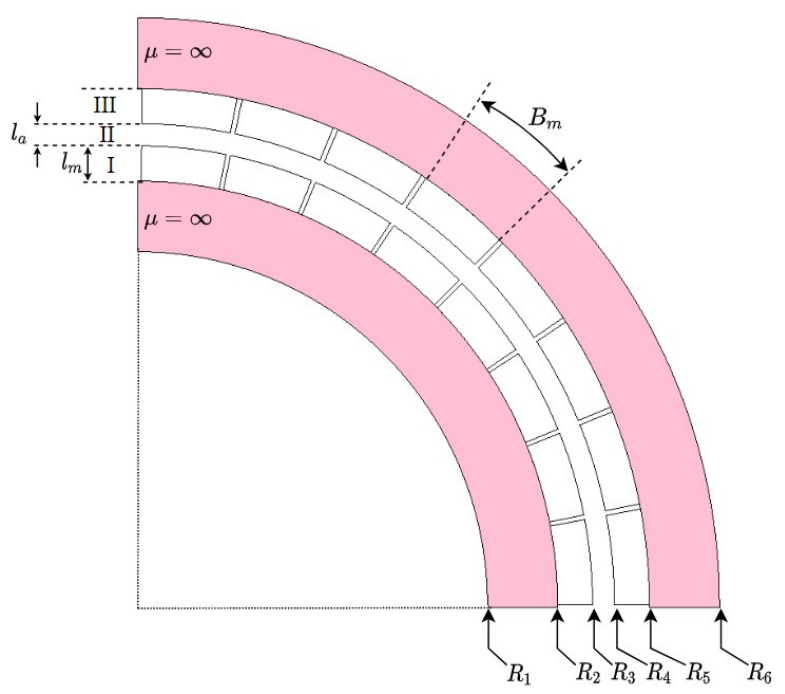

Fig. 2. 2D schematic of the radial MC with size parameters

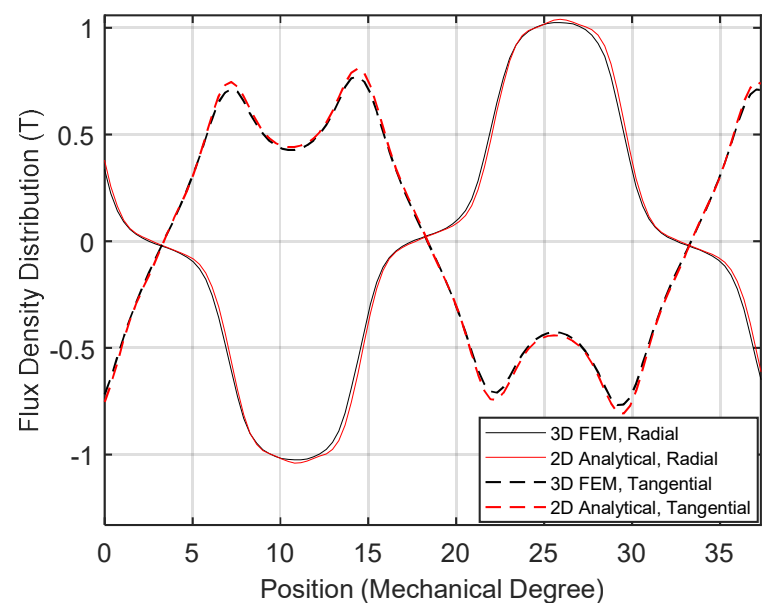

Fig. 3. Flux density comparison between the 2D analytical method and 3D FEM.

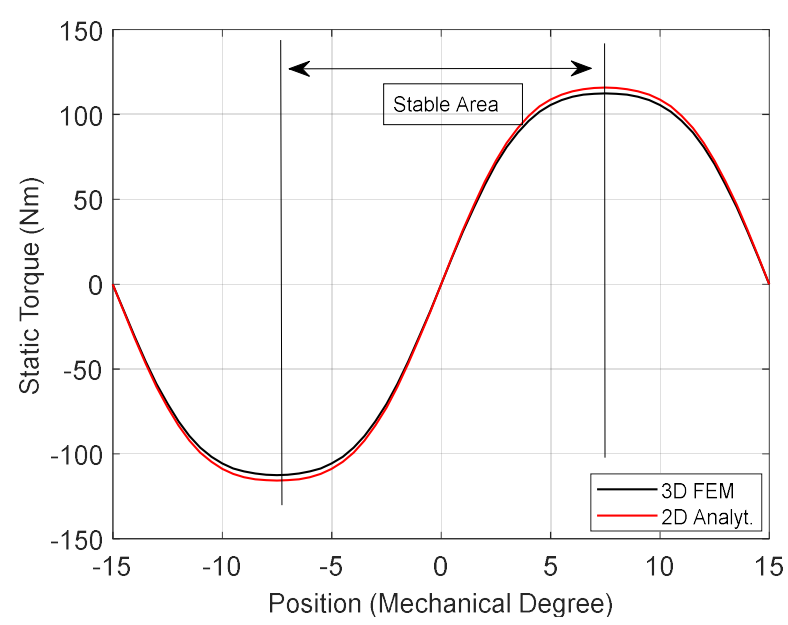

Fig. 4. The static torque comparison of the radial MC between the 2D analytical methods and 3D FEM. 
The first trade-off analysis to be considered observes the effects of the PM thickness against different pole-pair numbers, as shown in Fig. 5. It should be noted that the inner radius of the inner PM, $R_{2}$, is accepted $65 \mathrm{~mm}$ with 2 $\mathrm{mm}$ airgap thickness $l_{a}$ and $15 \mathrm{~mm}$ active length $l_{s}$. The values of the PM thickness range from 1 to $10 \mathrm{~mm}$ with 1 $\mathrm{mm}$ difference, while the pole-pair numbers are varied between 2 and 30 with 1 pole-pair difference. The results indicate that any changes in the PM thickness lead to a circumferential difference which causes a variance in the pole-pair numbers for the best peak static torque. For instance, at a $1 \mathrm{~mm}$ PM thickness, the best peak static torque is observed at 30 pole-pair number, whereas at $10 \mathrm{~mm}$ PM thickness, it is provided with 10 pole-pair number.

Similar behavior is reported in Fig. 6 for the peak static torque by changing the airgap thickness in comparison with pole-pair numbers. The PM thickness, the inner radius of the $\mathrm{PM}$, and the active lengths are $4 \mathrm{~mm}, 65 \mathrm{~mm}, 15 \mathrm{~mm}$, respectively. The analysis is concluded by changing the airgap thickness between $1 \mathrm{~mm}$ and $10 \mathrm{~mm}$ while the polpair numbers are kept similar with the previous analysis.

In contrast, Fig. 7 clearly confirm that the active length has no influence on the pole-pair numbers where $l_{a}, l_{m}$ and $R_{2}$ are $2.5 \mathrm{~mm}, 4 \mathrm{~mm}$ and $65 \mathrm{~mm}$, respectively. The peak static torque follows the same trend for any value of the active length. The figure is obtained with an active length between $10 \mathrm{~mm}$ and $50 \mathrm{~mm}$, stepping $5 \mathrm{~mm}$. Thus, the results conclude that longitudinal differences do not change the peak static torque trend developed by any pole-pair numbers. However, circumferential differences cause variation on the pole-pair numbers in order to produce the best peak static torque.

The final step to select the design parameters is obtained by changing the overall circumferential radius of the radial MC. The analysis is carried out by changing the inner radius of the inner PM between $40 \mathrm{~mm}$ and $50 \mathrm{~mm}$ with a $2 \mathrm{~mm}$ difference when the PM thickness is $4 \mathrm{~mm}$ and the axial length is $30 \mathrm{~mm}$. Based on the trade-off analysis, the $30 \mathrm{~mm}$ active length with $4 \mathrm{~mm}$ PM thickness can develop $100 \mathrm{Nm}$ required torque at $2.5 \mathrm{~mm}$ airgap thickness as shown in Fig.8. Thus, the values are employed for comparison and validation purposes with $3 \mathrm{D}$ FEM by considering pole-pair numbers between 2 and 30. The results are demonstrated in Fig. 9. The radial MC size parameters are finalized and given in Table II.

TABLE II

THE PARAMETERS OF 100 Nm RADIAL MC

\begin{tabular}{|c|c|}
\hline Parameters & Values \\
\hline Max. Static Torque (Nm) & 100 \\
\hline Max. Operating Speed (rpm) & 1500 \\
\hline Pole-Pairs Number & 16 \\
\hline Airgap Thickness $(\mathrm{mm})$ & 2.5 \\
\hline PM Thickness $(\mathrm{mm})$ & 4 \\
\hline Axial Length $(\mathrm{mm})$ & 30 \\
\hline Inner Ring Radius $(\mathrm{mm})$ & 40 \\
\hline Outer Ring Radius $(\mathrm{mm})$ & 66.5 \\
\hline Back Iron Length $(\mathrm{mm})$ & 8 \\
\hline PM Openings & $95 \%$ \\
\hline
\end{tabular}

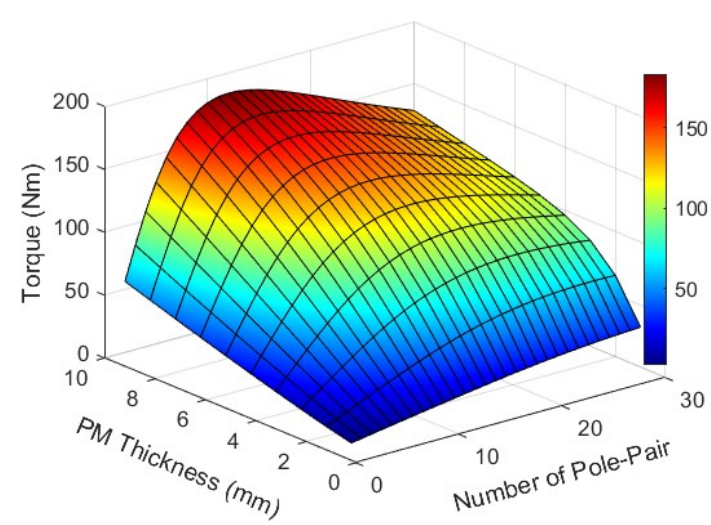

Fig. 5. Maximum static torque as function of both PM thickness and pole pair number.

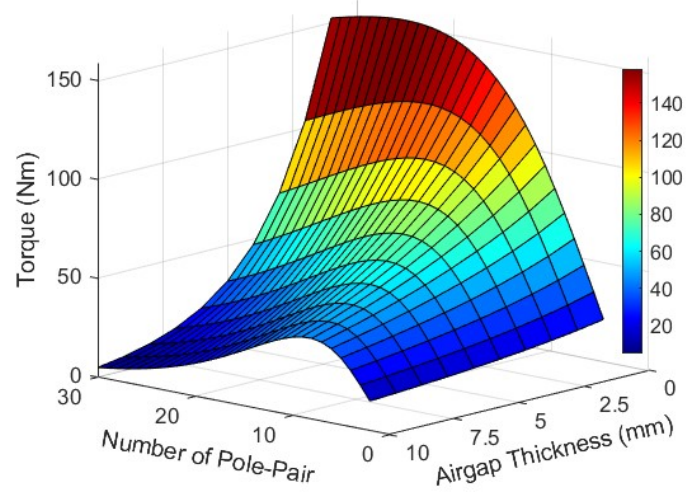

Fig. 6. Maximum static torque as function of both airgap thickness and pole pair number.

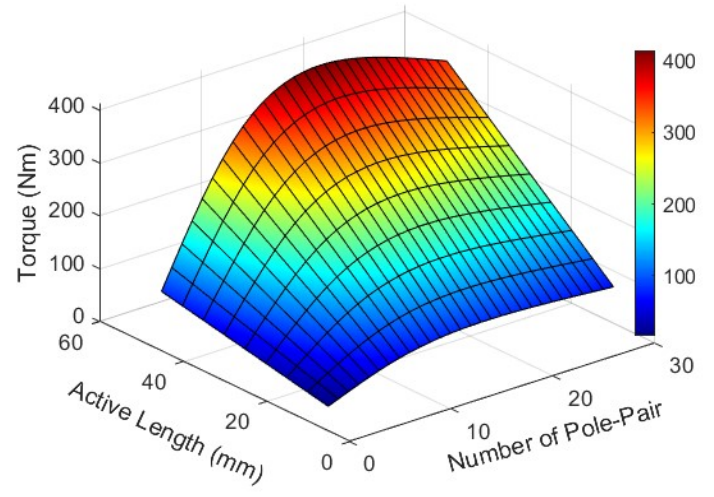

Fig. 7. Maximum static torque as function of both active length and pole pair number.

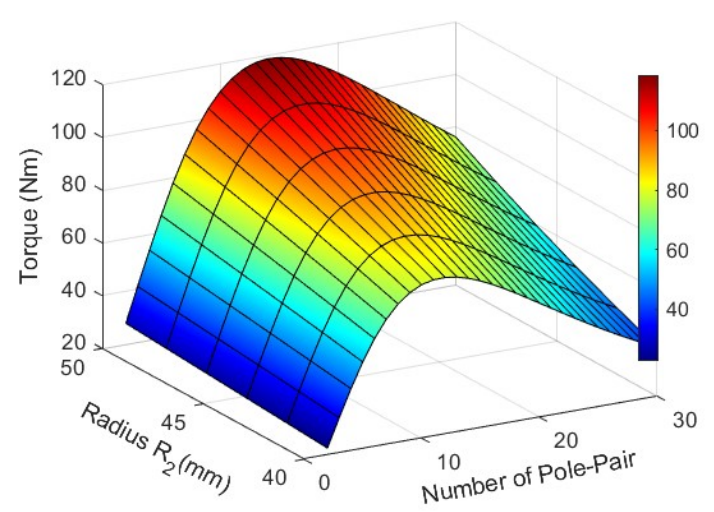

Fig. 8. Maximum static torque as function of both inner radius of the inner $\mathrm{PM}$ and pole pair number. 


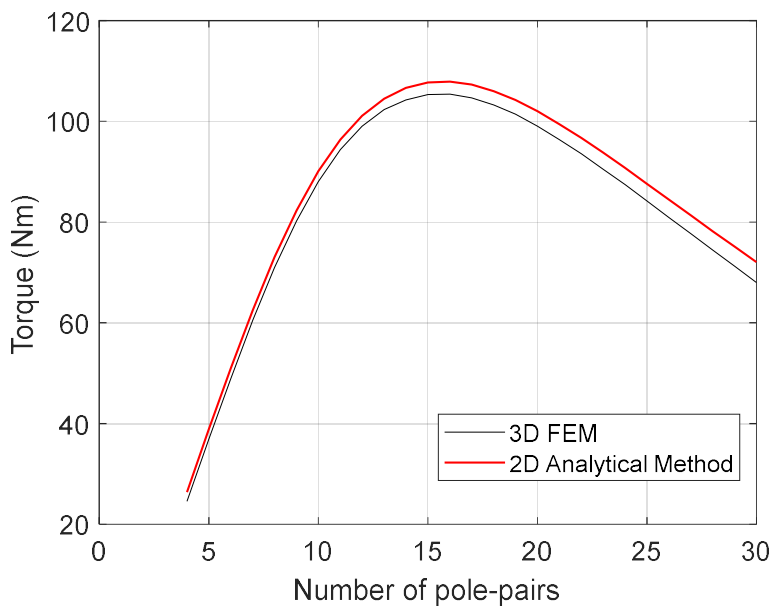

Fig. 9. The peak static torque comparison between the $2 \mathrm{D}$ analytical method and 3D FEM.

\section{DYNAMIC PERFORMANCE}

It is well known that stiffness and rigidity on a torque/speed transferring shaft play very important roles in mechanical systems. The problems due to low stiffness and damping in mechanical systems are numerous and can cause significant failures [23]. When the materials are subjected to a force/torque, they undergo deformations in their structure. The deformation changes materials' stiffness non-linearly. In fact, the contactless torque/speed transmissions can be implemented as two-inertia systems according to the dynamics theory. The dynamic representation of two-inertia systems interconnecting with a torsion spring is represented in Fig. 10a where $\omega_{m}$ is the motor angular velocity, $\omega_{L}$ is the load angular velocity, $T_{m}$ is the motor-side torque and $T_{L}$ is the load-side torque. The component between the motor and load sides shown in Fig. 9a is mechanically compliant for the MCs and has a torsional stiffness represented with $K_{s}$ in $\mathrm{Nm} / \mathrm{rad}$. The block diagram of the two-inertia system is provided in Fig. 10b.

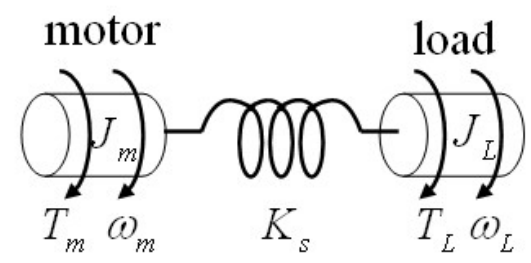

(a)

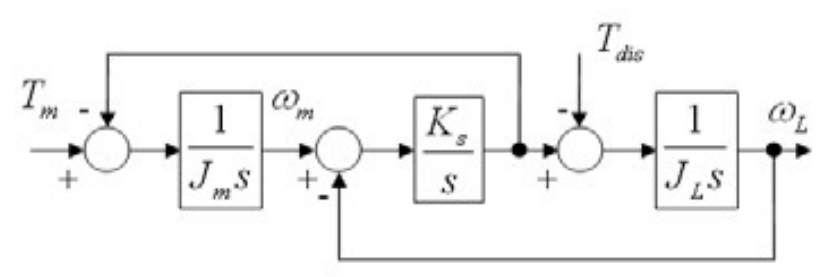

(b)

Fig. 10. (a) Dynamic representation of a two-inertia system, (b) its block diagram.
Each material has its own torsional stiffness characteristics which denotes its rigidity, i.e. a higher value of a torsional stiffness resists to a higher load. In general, the torsional stiffness of a cylindrical shaft with a radius $R$ can be calculated by using (1), where $G$ is the rigidity modulus of the material (Young's modulus for various materials in $\mathrm{GPa}), J$ is torsional constant with respect to material shape and $L$ is the length of the shaft.

$$
K_{s}=\frac{G \cdot J}{L}
$$

with

$$
J=\frac{\pi \cdot R^{4}}{2}
$$

According to (1), a two-inertia system with a shaft of 1 $\mathrm{cm}$ radius and $50 \mathrm{~cm}$ length has a torsional stiffness for different materials revealed in Table III.

TABLE III

THE TORSIONAL STIFFNESS VALUES OF THE SELECTED MATERIALS

\begin{tabular}{|c|c|c|}
\hline Material & $\begin{array}{c}G \\
(\mathrm{Gpa})\end{array}$ & $\begin{array}{c}K_{s} \\
(\mathrm{Nm} / \mathrm{rad})\end{array}$ \\
\hline High-strength concrete & 30 & 942.48 \\
\hline Magnesium metal & 45 & 1413.72 \\
\hline Aluminium & 69 & 2167.7 \\
\hline Bronze & 96 & 3015.9 \\
\hline Steel & 200 & 6283.2 \\
\hline
\end{tabular}

Similarly, for the dynamic investigations, the MC designed in the previous section is implemented in the twoinertia system. The equivalent circuit of the MC is presented in the two-inertia system with its torsional stiffness. In fact, the MC has a non-linear torsional stiffness characteristic that changes with angular displacement between motor and load sides of the coupling. According to the research in [22], the non-linear stiffness is given in (3).

$$
K_{s}=p T_{\max } \cos \left(p\left(\theta_{M}-\theta_{L}\right)\right)
$$

$T_{\max }$ is the peak static torque which is $100 \mathrm{Nm}$ for the proposed radial MC, $p$ represents the number of pole-pairs, and $\theta_{M}$ and $\theta_{L}$ are the motor and load side angular positions, respectively. When a load is applied to the system, the displacement angle $\theta_{D}=\left(\theta_{M}-\theta_{L}\right)$ between the motor and load sides of the MC changes. Meanwhile, the stiffness decreases according to (3). After a certain amount of a load, the existing stiffness cannot resist the load and the poles inevitably slip. On the other hand, according to [18], the torsional stiffness is usually accepted as linear in a classical two-inertia systems at the beginning. Thus, the designed radial $\mathrm{MC}$ is also considered to have an ideal linear torsional spring with a stiffness $K_{i}(\mathrm{Nm} / \mathrm{rad})$ and behaves linearly within the stable area as shown in Fig. 11. The linear torsional stiffness is given in (4).

$$
K_{i}=p T_{\max }
$$


As a result of that, the generated torque by the PMs with respect to the displacement angle can theoretically be specified by (5).

$$
T_{s}=T_{\max } \sin \left(p\left(\theta_{D}\right)\right)
$$

where the transmitted torque by the PMs is represented by $T_{c}$. The dynamic investigation is carried out by considering both linear and non-linear torsional stiffness characteristics. In order to complete the dynamic analysis, an induction machine (IM) is connected as a prime mover on the motor side. The performance parameters of the IM are given in Table IV. The motor and load sides of the radial MC is assumed as the outer and inner rings, respectively. The total inertia of the motor side is $0.6 \mathrm{~kg} . \mathrm{m}^{2}$; i.e. the IM and the outer ring of the $\mathrm{MC}$, while the load side inertia is 0.2 $\mathrm{kg} \cdot \mathrm{m}^{2}$ which is the summation of the load inertia and the inner ring of the MC. The inertias of the outer and inner rings of the MC are 37.9 and $16.8 \mathrm{~kg} . \mathrm{cm}^{2}$, respectively.

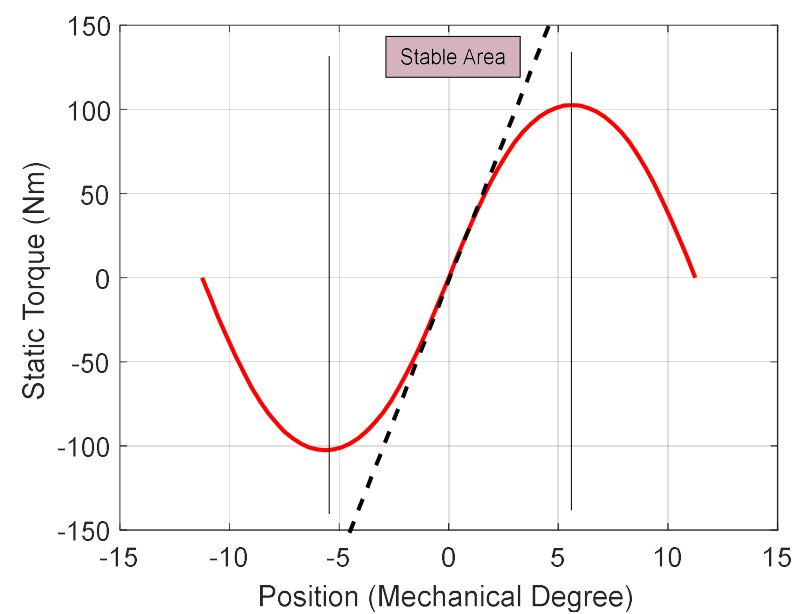

Fig. 11. The static torque with respect to displacement angle; linear spring (dashed line), magnetic coupling (solid line)

TABLE IV

THE $22 \mathrm{~kW}$ IM PARAMETERS

\begin{tabular}{|c|c|}
\hline Parameter Description & Values \\
\hline Stator Voltage & $415 \mathrm{~V}(\Delta)$ \\
\hline Stator Frequency & $50 \mathrm{~Hz}$ \\
\hline Number of Poles & 4 \\
\hline Stator Resistance & $0.6 \Omega$ \\
\hline Rotor Resistance & $0.398 \Omega$ \\
\hline Stator Leakage Inductance & $111 \mathrm{mH}$ \\
\hline Rotor Leakage Resistance & $110 \mathrm{mH}$ \\
\hline Magnetizing Inductance & $106 \mathrm{mH}$ \\
\hline
\end{tabular}

The analysis aims to investigate the behaviour of the coupling under different step-load conditions. As it is known that the radial MC is designed to produce a $100 \mathrm{Nm}$ peak static torque with $1500 \mathrm{rpm}$ rated speed. The two-inertial system exhibits the IM and the outer ring in the motor side and the load inertia and the inner ring in the load side where the torque/speed is transmitted via compliant drivetrain which in this perspective is assumed a torsion spring. In a linear torsion spring, the displacement angle does not change the stiffness constant, i.e. $K_{i}=1600$ (Nm/rad). However, in case of the non-linear torsional stiffness, the constant is no longer constant and changes with the displacement angle. In this section, the IM is operated in open loop meaning that there is not a controller developed for the torque/speed control and it is fed by a 3-phase, $415 \mathrm{~V}$ and $50 \mathrm{~Hz}$ supply. The analysis is carried out by adding step loads, i.e. $60 \mathrm{Nm}$ step-load disturbance while the IM runs at rated speed.

Fig. 12 clearly shows that the load disturbance $60 \mathrm{Nm}$ at 5 sec. and $100 \mathrm{Nm}$ at $10 \mathrm{sec}$. can still be delivered at $1500 \mathrm{rpm}$ speed demand. However, in fact, in real conditions, the dynamic representation of the radial $\mathrm{MC}$, which constitutes a motor and load in both sides, can be represented as a twoinertial system interconnecting with a highly compliance magnetic torsional spring with a non-linear stiffness $K_{s}$, as seen in (3). Therefore, Fig. 13 is reported under non-linear condition and with a step-load disturbance, i.e. $60 \mathrm{Nm}$ at 5 sec. and $80 \mathrm{Nm}$ at $10 \mathrm{sec}$. It can be seen that due to the displacement angle, the torsional stiffness shows non-linear characteristics and changes the spring constant. Thus, the radial MC goes to slip-region. The pole-slipping is undesired condition which happens when the inner and outer rings displace more than the MC's permissible maximum shift angle which is often called unstable area as in Fig. 11.

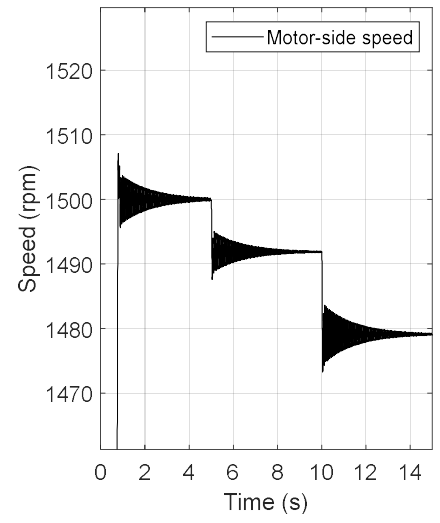

(a)

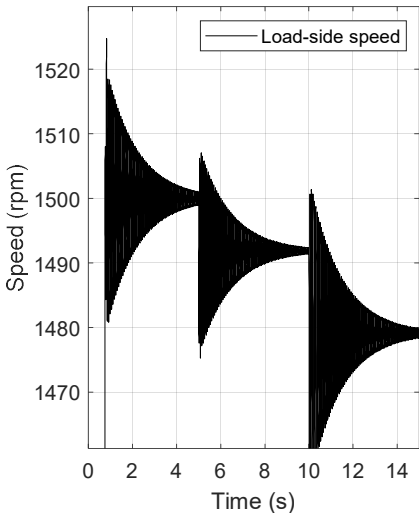

(b)
Fig. 12. The speed response of the system with a linear spring constant (a) motor side, (b) load side.

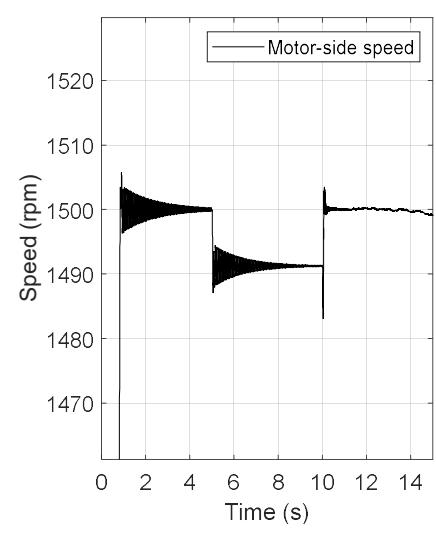

(a)

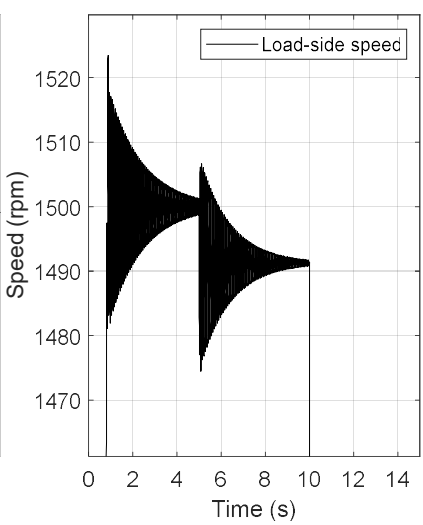

(b)
Fig. 13. The speed response of the system with a non-linear spring constant (a) motor side, (b) load side. 


\section{CONCLUSION}

This paper reports the design process and analysis of a $100 \mathrm{Nm}$ radial MC. In particular, the 2D analytical method has been applied to perform trade-off analysis of the most important design parameters, i.e. pole-pair numbers, airgap thickness, overall radius, active length, and PM thickness. Since the 2D analytical method allows a quick evaluation, the size parameters are obtained and compared with 3D FEM for validation purposes. The paper has addressed clearly how the aforementioned parameters change the behavior of the static torque. Later, the dynamic investigation of the final radial $\mathrm{MC}$ has been completed under linear and non-linear behavior of the torsional stiffness characteristics. According to the data obtained by the dynamic analysis, the peak static torque must be carefully decided since there is a safety margin which was detected around $80 \%$ of the static torque meaning that exceeding the $80 \%$ of the static torque may cause poleslipping phenomena. The safety margin, furthermore, is highly affected by the systems' inertia. The motor and load side inertia play significant role of the MC design process.

\section{ACKNOWLEDGMENT}

This project received funding from the Clean Sky 2 Joint Undertaking under the European Union's Horizon 2020 research and innovation programme under grant agreements no 821023 and no. 807081. This work was also partially funded by the University of Nottingham Propulsion Futures Beacon.

\section{REFERENCES}

[1] J. Rizk, M. H. Nagrial and A. Hellany, "Analysis and design of magnetic torque couplers and magnetic gears," The 4th International Power Electronics and Motion Control Conference, 2004. IPEMC 2004., Xi'an, 2004, pp. 1799-1804 Vol.3.

[2] A. Al-Timimy et al., "Design and optimization of a high power density machine for flooded industrial pump," 2016 XXII International Conference on Electrical Machines (ICEM), Lausanne, 2016, pp. 1480-1486.

[3] A. Al-Timimy, G. Vakil, M. Degano, P. Giangrande, C. Gerada and M. Galea, "Considerations on the Effects That Core Materia Machining Has on an Electrical Machine's Performance," in IEEE Transactions on Energy Conversion, vol. 33, no. 3, pp. 1154-1163, Sept. 2018.

[4] Radzevich, S. P., \& Dudley, D. W. (2012). Dudley's handbook of practical gear design and manufacture. Boca Raton, Fla: CRC Press.

[5] K. Atallah and D. Howe, "A novel high-performance magnetic gear," in IEEE Transactions on Magnetics, vol. 37, no. 4, pp. 2844-2846, July 2001.

[6] K. Atallah, J. Wang, and D. Howe, "A high-performance linear magnetic gear," J. Appl. Phys., vol. 97, no. 10, pp. 10N516-10N5163, May 2005.

[7] K. Atallah, S. D. Calverley, and D. Howe, "Design, analysis and realisation of a high-performance magnetic gear," Proc. IEEElectric Power Appl., vol. 151, no. 2, pp. 135-143, Mar. 2004.

[8] P. O. Rasmussen, T. O. Andersen, F. T. Jorgensen, and O. Nielsen, "Development of a high-performance magnetic gear," IEEE Trans. Ind. Appl., vol. 41, no. 3, pp. 764-770, May/Jun. 2005.

[9] J. Rens, K. Atallah, S. D. Calverley, and D. Howe, "A novel magnetic harmonic gear," IEEE Trans. Ind. Appl., vol. 46, no. 1, pp. 206-212, Jan./Feb. 2010.

[10] M. Lukic, P. Giangrande, A. Hebala, S. Nuzzo and M. Galea, "Review, Challenges, and Future Developments of Electric Taxiing Systems," in IEEE Transactions on Transportation Electrification, vol. 5, no. 4, pp. 1441-1457, Dec. 2019.
[11] P. Giangrande, V. Madonna, G. Sala, A. Kladas, C. Gerada and M. Galea, "Design and Testing of PMSM for Aerospace EMA Applications," IECON 2018 - 44th Annual Conference of the IEEE Industrial Electronics Society, Washington, DC, 2018, pp. 2038-2043.

[12] C. I. Hill, S. Bozhko, Tao Yang, P. Giangrande and C. Gerada, "More Electric Aircraft Electro-Mechanical Actuator Regenerated Power Management," 2015 IEEE 24th International Symposium on Industrial Electronics (ISIE), Buzios, 2015, pp. 337-342.

[13] V. Madonna, P. Giangrande, A. Walker and M. Galea, "On the Effects of Advanced End-Winding Cooling on the Design and Performance of Electrical Machines," 2018 XIII International Conference on Electrical Machines (ICEM), Alexandroupoli, 2018, pp. 311-317.

[14] W. Wu, H. C. Lovatt and J. B. Dunlop, "Analysis and design optimisation of magnetic couplings using 3D finite element modelling," in IEEE Transactions on Magnetics, vol. 33, no. 5, pp. 4083-4094, Sept. 1997.

[15] J. F. Charpentier and G. Lemarquand, "Study of PermanentMagnet Couplings with Progressive Magnetization Using an Analytical Formulation," IEEE Trans. Magn., vol. 35, no. 5, pp. 4206-4217, Sep. 1999.

[16] M. Galea, P. Giangrande, V. Madonna and G. Buticchi, "ReliabilityOriented Design of Electrical Machines: The Design Process for Machines' Insulation Systems MUST Evolve," in IEEE Industrial Electronics Magazine, vol. 14, no. 1, pp. 20-28, March 2020.

[17] P. Giangrande, V. Madonna, S. Nuzzo and M. Galea, "Design of Fault-Tolerant Dual Three-Phase Winding PMSM for Helicopter Landing Gear EMA," 2018 IEEE International Conference on Electrical Systems for Aircraft, Railway, Ship Propulsion and Road Vehicles \& International Transportation Electrification Conference (ESARS-ITEC), Nottingham, 2018, pp. 1-6.

[18] R. G. Montague, C. Bingham and K. Atallah, "Magnetic Gear PoleSlip Prevention Using Explicit Model Predictive Control," in IEEE/ASME Transactions on Mechatronics, vol. 18, no. 5, pp. 1535-1543, Oct. 2013.

[19] R. G. Montague, C. M. Bingham, and K. Atallah, "Characterisation and modelling of magnetic couplings and gears for servo control systems," in Proc. 5th IET Int. Conf.Power Electron., Mach. Drives, 2010, pp. 1-6.

[20] R. Montague, C. Bingham and K. Atallah, "Servo Control of Magnetic Gears," in IEEE/ASME Transactions on Mechatronics, vol. 17, no. 2, pp. 269-278, April 2012.

[21] P. Giangrande et al., "Considerations on the Development of an Electric Drive for a Secondary Flight Control Electromechanical Actuator," in IEEE Transactions on Industry Applications, vol. 55, no. 4, pp. 3544-3554, July-Aug. 2019.

[22] P. Giangrande, C. I. Hill, S. V. Bozhko and C. Gerada, "A novel multi-level electro-mechanical actuator virtual testing and analysis tool," 7th IET International Conference on Power Electronics, Machines and Drives (PEMD 2014), Manchester, 2014, pp. 1-6.

[23] R. G. Montague, C. M. Bingham, and K. Atallah, "Magnetic gear overload detection and remedial strategies for servo-drive systems," in Proc. Int. Symp. Power Electron. Electr. Drives Autom. Motion, 2010, pp. 523-528.

[24] Y. Akcay, P. Giangrande, M. Galea, C. Gerada, "Comparative Analysis between Axial and Coaxial Magnetic Couplings," accepted for publication in 10th IET International Conference on Power Electronics, Machines and Drives, 2020.

[25] S. A. Odhano, P. Giangrande, R. Bojoi and C. Gerada, "Selfcommissioning of interior permanent magnet synchronous motor drives with high-frequency current injection," 2013 IEEE Energy Conversion Congress and Exposition, Denver, CO, 2013, pp. 38523859 . 